\title{
Kajian Lokasi Pos Induk Pemadam Kebakaran terhadap Bencana Kebakaran di Kota Mataram
}

\author{
*Fariz Primadi H, Baiq Harly Widayanti, Agus Kurniawan, Ardi Yuniarma, dan Sri Apriani P. Lestari \\ Program Studi Perencanaan Wilayah \& Kota, Univ. Muhammadiyah Mataram \\ *fariz.primadi@gmail.com
}

\begin{abstract}
INFO ARTIKEL
Riwayat Artikel:

Diterima:12-7-2018

Disetujui:2-8-2018

Kata Kunci:

Analisis Jaringan

Kebakaran

\section{ABSTRAK}

Abstrak: Penelitian bertujuan mengidentifikasi kondisi eksisting pos induk pemadam kebakaran, tingkat kerawanan kebakaran dan penentuan alternatif solusi pemecahan masalah. Penelitian menggunakan metode deskriptif serta analisis deskriptif dan analisis jaringan. Hasil penelitian menunjukan kondisi Pos Induk Pemadam Kebakaran cukup memadai, baik dari aspek kelayakan fisik bangunan maupun kemampuan pelayanan. Frekuensi kejadian kebakaran tahun 2016, rata-rata terjadi 2 kasus setiap bulannya. Daerah rawan kebakaran secara umum didominasi oleh daerah yang memiliki tingkat resiko kebakaran sedang. Alternatif solusi masalah lokasi pos induk pemadam kebakaran yaitu penambahan jumlah infrastruktur pemadam kebakaran, seperti hidran, Alat Pemadam Api Ringan (APAR), Smoke Detector, Automatic Gurgoyle.
\end{abstract}

Pos Induk

\begin{abstract}
The research aims to identify the existing conditions of the fire department main post, the level of fire vulnerability and the determination of alternative problem solving solutions. The study uses descriptive methods and descriptive analysis and network analysis. The results showed the condition of the Fire Post Main Post was quite adequate, both from the aspect of the physical feasibility of the building and service capabilities. Frequency of fire events in 2016, on average there are 2 cases each month. Fire-prone areas in general are dominated by areas that have a moderate risk of fire. Alternative solutions to the problem of the location of the firefighting main post, namely the addition of the number of fire fighting infrastructure, such as fire hydrants, Fire Extinguisher (APAR), Smoke Detector, Automatic Gurgoyle.
\end{abstract}

\section{A. LATAR BELAKANG}

Dewasa ini perkembangan penyelengaraan bangunan di perkotaan semakin kompleks baik dari segi intensitas, teknologi, maupun kebutuhan prasarana dan sarana. Dengan demikian permasalahan yang dihadapi juga semakin beragam, salah satu diantaranya adalah titik rawan kebakaran perkotaan. Di beberapa kota besar di Indonesia seperti Jakarta dan Surabaya seringkali terjadi peristiwa kebakaran yang kebanyakan terjadi pada kawasan padat hunian seperti permukiman, pusat perbelanjaan (Mal), pasar dan gedung perkantoran. Upaya penanggulangan kebakaran seringkali terlambat dilakukan karena kurang siapnya aparat maupun peralatan pemadam kebakaran, kondisi lalu lintas yang padat sehingga tidak bisa dilalui oleh kendaraan pemadam kebakaran, titik pengambilan air tidak berfungsi (antara lain banyak hidrat yang rusak/kurang berfungsi), dan lain-lain. Kerugian yang ditimbulkan akibat bencana kebakaran tersebut bukan hanya materi saja tetapi seringkali merenggut korban jiwa. Untuk itu upaya pencegahan dan penanggulangan kebakaran di perkotaan menjadi hal yang penting dan mendesak, dimana keselamatan masyarakat yang berada di dalam bangunan dan lingkungan harus menjadi pertimbangan utama, agar dapat melakukan kegiatan dan meningkatkan produktifitas serta kualitas hidupnya.

Perkembangan Kota Mataram dari tahun ke tahun semakin maju ditandai dengan hadirnya berbagai kegiatan perekonomian. Peningkatan kegiatan masyarakat kerap menimbulkan permasalahan yang terjadi di perkotaan, salah satunya potensi kebakaran. Sampai saat ini Kota Mataram khususnya ataupun seluruh kota-kota utama yang ada di provinsi Nusa Tenggara Barat belum memiliki suatu program yang mengatur sistem penangulangan kebakaran, sehingga untuk mengimbangi pertumbuhan dan perkembangan kota ini perlu dilakukan suatu evaluasi sebagai dasar perbaikan strategi dalam menghadapi bencana kebakaran. Beberapa permasalahan yang terkait dengan upaya pencegahan dan penanggulangan bahaya kebakaran pada bangunan dan lingkungan di Kota Mataram, antara lain adalah: 
a. Terbatasnya sumber air : danau, sungai, sumur kebakaran, tendon air, hidran kota, dan sebagainya, guna keperluan pemadaman;

b. Luas wilayah yang dilayani oleh pos pemadam kebakaran kota tidak sebanding dengan jumlah pos kebakaran yang ada;

c. Infrastruktur kota belum memadai, yaitu penataan hidran kota untuk keperluan pemadaman;

d. Jumlah dan ketrampilan personil pemadam belum memadai;

e. Kelembagaan dan tupoksi penanganan kebakaran masih dirasakan lemah.

Fenomena yang menggambarkan bahwa perkembangan perkotaan akan membawa dampak serta permasalahan seperti kebakaran merupakan tantangan tersendiri bagi para perencana perkotaan. Untuk itulah penelitian ini berusaha untuk mengidentifikasi kondisi eksisting pos induk pemadam kebakaran Kota Mataram, serta daerah rawan kebakaran guna memilih atau menentukan alternatif solusi pemecahan masalah lokasi Pos Induk Pemadan Kebakaran terhadap bencana kebakaran di wilayah Kota Mataram.

\section{B. METODE PENELITIAN}

Penelitian ini menggunakan metode pendekatan deskriptif yang bertujuan untuk menjelaskan aspekaspek yang relevan dengan fenomena yang diamati. Data diperoleh dari berbagai macam sumber data sekunder (publikasi relevan) serta data primer yag merupakan hasil wawancara terhadap responden. Adapun analisis yang dilakukan terdiri dari beberapa tahapan, yaitu:

\section{Analisis Deskriptif}

Metode statistik yang digunakan dalam analisa deskriptif penelitian ini adalah:

a. Metode statistik Nilai Presentase, untuk mempersentasekan jawaban-jawaban yang diberikan oleh responden pada item-item pertanyaan kuisioner. Untuk menghitung nilai presentase digunakan rumus [1]:

$$
\text { Nilai Presentase }=\frac{\text { Nilai Data }}{\text { Jumlah total data }} \times 100 \%
$$

b. Metode statistik Nilai rata-rata (Mean), mengetahui frekuensi dari setiap jawaban pada item-item pertanyaan tertentu yang diberikan oleh responden. Dengan demikian akan diketahui manakah dari setiap item pada masing-masig pertanyaan yang lebih prioritas keadaanya. Untuk menghitung mean (X), rumus yang digunakan adalah [1]:

$$
\text { Mean }=\frac{X}{n}
$$

$$
\text { Dimana : } \begin{aligned}
\mathrm{X} & =\text { Data ke } \mathrm{i} \\
n & =\text { banyaknya data }
\end{aligned}
$$

\section{Analisis Jaringan (Grid Analysis)}

Analisis jaringan merupakan salah satu metode dalam pengambilan keputusan, yaitu proses menetukan satu alternative pilihan atas beragam pilihan.

\section{HASIL DAN PEMBAHASAN}

\section{Kondisi Eksisting Pos Induk Pemadam} Kebakaran

a. Lokasi Pos Induk Pemadam Kebakaran dan Fasilitas Penunjang

Kota Mataram, dengan luas 61,30 $\mathrm{Km}^{2}$ dan berpenduduk 473.543 jiwa yang tersebar di 6 wilayah Kecamatan, memiliki 1 Pos Induk Pemadam Kebakaran (PMK) yang terletak di Kelurahan Cakra Barat, tepatnya di jalan Bung Hatta No.2 Mataram. Pos Induk Pemadam Kebakaran Kota Mataram ini berupa gedung bangunan representatif yang memiliki 7 unit mobil Pemadam Kebakaran dengan kondisi siap operasi. Fasilitas lainya terdiri dari pakaian tahan api untuk para personil, masker oksigen, selan air untuk pemadam kebakaran, dan beberapa peralatan pemadam portable. Gedung Pos Induk Pemadam Kebakaran ini juga di lengkapi oleh beberapa ruangan tempat tidur sebagai upaya meningkatkan kesiapan personil dalam menghadapi situasi darurat akibat kebakaran kapan pun juga.

b. Kondisi Hidran di Kota Mataram

Wilayah Kota Mataram secara umum hanya memiliki beberapa hidran dengan kondisi yang kurang terawat dan terletak hanya pada titik-titik tertentu yang dianggap memiliki potensi kebakaran yang tinggi seperti di permukiman padat, sekitar kantor-kantor pemerintahan, dan pusat-pusat perdagangan yang dilintasi jaringan pipa PDAM, karena penentuan lokasi hidran diwilayah Kota Mataram adalah merupakan rujukan Kantor Pemadam Kebakaran ke Pihak PDAM sebagai penyedia sarana Hidran. Beberapa wilayah yang belum dilayani jaringan PDAM sampai saat ini secara umum, belum dilengkapi oleh ketersediaan hidran.

c. Potensi Air Cadangan

Sebagai salah satu sarana pemadam kebakaran, sumber air berpotensi dijadikan sebagai alat melakukan pemadaman. Sumber air yang ada di wilayah Kota Mataram sangat beragam mulai dari pemanfaatan air sungai maupun aliran irigasi yang memiliki debit air konstan sepanjang tahun. Untuk tiap-tiap titik jika terjadi kebakaran, telah terjangkau oleh sumber air cadangan yaitu sungai yang membelah Kota Mataram. Sungai-sungai tersebut adalah sungai Meninting di bagian utara, sungai Ancar, sungai Jangkok di bagian tengah dan sungi Bernyok di bagian selatan. 
d. Jangkauan Kerja Dan Kelembagaan Pemadam Kebakaran Kota Mataram

Jangkauan kerja dan kelembagaan pemadam kebakaran Kota Mataram secara administrasi hanya sebatas pada wilayah Kota Mataram saja, akan tetapi jika terjadi kebakaran yang memiliki tingkat kebakaran berat yang berada di wilayah kerjanya, kantor pemadam kebakaran Kota Mataram akan ikut menangani kejadian tersebut tergantung koordinasi dengan satuan pemadaman kebakaran provinsi NTB. Jumlah personil yang terdaftar sebagai petugas pemadam kebakaran sejumlah 45 orang dimana terbagi menjadi 3 sistem shift kerja, masing-masing 15 orang untuk 1 kali jaga selama 24 jam penuh. Struktur organisasi kantor pos induk pemadam kebakaran kota mataram terdiri dari [2]:

a. Kepala pemadam kebakaran

b. Teknis sekaligs jurumudi

c. Komandan regu lapangan

d. Anggota

\section{Frekuensi Kejadian Kebakaran Di Kota Mataram}

Kejadian kebakaran yang terjadi 4 tahun terakhir di Kota Mataram berjumlah 93 kasus yang terjadi atas kasus kebakaran hebat/tinggi, sedang maupun kecil. Kebanyakan kasus kebakaran ini terjadi di perumahan dan pasar yang memcapai persentase lebih dari 50\% [3]. Sebagian besar kegiatan perdagangan / pertokoan di Kota Mataram berlokasi di Kecamatan Cakranegara, dimana letak bangunannya berhimpitan dengan aktivitas kegiatan yang cukup kompleks. Hal ini menyebabkan risiko untuk terjadinya kebakaran cukup besar.

Tabel 1

Kejadian kebakaran di kota mataram tahun 2013-2016

\begin{tabular}{llcccc}
\hline \multirow{2}{*}{ No. } & \multirow{2}{*}{ Kecamatan } & \multicolumn{5}{c}{ Tahun } \\
\cline { 3 - 6 } & & $\mathbf{2 0 1 3}$ & $\mathbf{2 0 1 4}$ & $\mathbf{2 0 1 5}$ & $\mathbf{2 0 1 6}$ \\
\hline 1. & Sandubaya & 1 & 3 & 2 & 2 \\
2. & Cakranegara & 4 & 5 & 9 & 7 \\
3. & Mataram & 2 & 4 & 4 & 7 \\
4. & Selaparang & 2 & 2 & 6 & 3 \\
5. & Ampenan & 7 & 4 & 7 & 2 \\
6. & Sekarbela & 1 & 1 & 5 & 3 \\
\hline Jumlah & 17 & 19 & 34 & 24 \\
\hline
\end{tabular}

Sumber: Dinas Pemadam Kebakaran Kota Mataram (2017)

\section{Pemetaan Daerah Rawan Kebakaran Di Kota Mataram}

Daerah rawan kebakaran untuk Kota Mataram secara umum masih didominasi oleh daerah yang memiliki tingkat resiko kebakaran sedang.

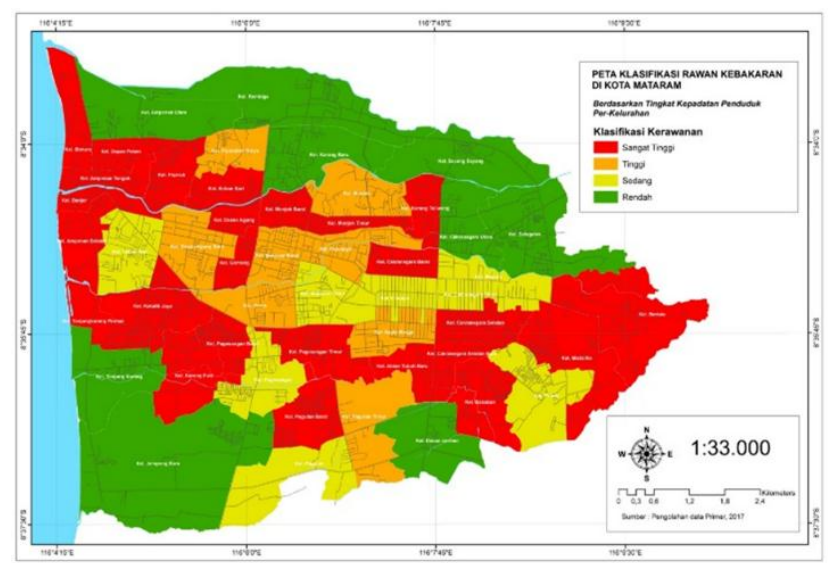

Gambar 1. Persebaran daerah rawan kebakaran

\section{Kelayakan Lokasi Pos Induk Pemadam Kebakaran dan Jangkauan Pelayanan (berdasarkan pendapat responden)}

Jawaban mengenai pembahasan dari permasalahan yang diuji dilakukan melalui wawancara secara langsung dengan responden penelitian agar hasil dan analisa yang didapatkan benar-benar obyektif. Pendapat responden mengenai permasalahan dapat diuraikan sebagai berikut:

a. Responden yang mengatakan bahwa kondisi pos induk pemadam kebakaran kota mataram yang ada pada saat ini masih layak adalah sebanyak 43 orang (94,6\%) dengan alasan yang dikemukakan secara garis besar adalah kondisi fisik bangunan pos induk pemadam kebakaran kota mataram masih bagus serta sarana prasarana kantor masih memadai. Sedangkan responden yang mengatakan bahwa kondisi pos induk pemadam kebakaran kota mataram yang ada pada saat ini sudah tidak layak adalah sebanyak 2 orang $(4,4 \%)$, dengan alasan yang dikemukakan secara garis besar adalah kondisi pos induk pemadam kebakaran kota mataram di tengah kota, sehingga terlalu ramai. Dari uraian tersebut, dapat disimpulkan bahwa kondisi pos induk pemadam kebakaran Kota Mataram yang ada pada saat ini pada umumnya masih layak.

b. Responden yang menyatakan lokasi pos induk pemadam kebakaran yag ada pada saat ini masih mampu melayani menjangkau seluruh wilayah kota mataram adalah sebanyak 41 orang (91,1\%), dengan alasan yang dikemukakan secara garis besar adalah lokasi pos induk pemadam kebakaran Kota Mataram mampu melayani menjangkau seluruh wilayah Kota Mataram karena telah direncanakan dengan baik, dengan catatan jika harus lalu lintas lancar. Sehingga permasalahan sebenarnya adalah bukan pada lokasinya tetapi pada kepadatan arus lalu lintas menuju dari lokasi pos induk pemadam kebakaran yang merupakan masalah kopleks dilibatkan banyak pihak dan tidak bias diselesaikan secara sepihak. Sedangkan 
rensponden menyatakan bahwa lokasi pos induk pemadam kebakaran yang ada pada saat ni sudah tidak mampu melayani menjangkau seluruh wilayah kota mataram adalah sebanyak 4 orang (8,9\%) dengan alasan yang dikemukakan secara garis besar adalah karena kendala kemacetan lalu lintas, kepadatan bangunan dan jumlah unit mobil pemadam kebakaran yang kurang memadai.

\section{Kajian Alternatif Solusi Penanganan bencana Kebakaran di Kota Mataram}

Analisis alternatif solusi penanganan bencana kebakaran di Kota Mataram dilakukan dengan metode analisis jaringan (grid analysis), Secara ringkas hasil analisis jaringan ditampilkan pada tabel berikut.

Tabel 3

Hasil Analisis Jaringan

FAKTOR PERTIMBANGAN

\begin{tabular}{|c|c|c|c|c|c|c|c|}
\hline \multirow[b]{2}{*}{$\begin{array}{l}\text { ALTERNATIF } \\
\text { SOLUSI }\end{array}$} & \\
\hline & $\mathbf{A}$ & $\mathbf{B}$ & $\mathbf{C}$ & $\mathbf{D}$ & $\mathbf{E}$ & $\mathbf{F}$ & $\underset{\mathbf{h}}{\text { Jumla }}$ \\
\hline Bobot & 3.0 & 2.7 & 2.8 & 3.0 & 2.8 & 2.7 & . \\
\hline $\begin{array}{l}\text { Pembangunan pos } \\
\text { induk pemadam } \\
\text { kebakaran baru }\end{array}$ & 7.7 & 7.2 & 7.5 & 7.7 & 7.5 & $7 \cdot 3$ & 44.9 \\
\hline $\begin{array}{l}\text { Pengembangan/pe } \\
\text { rluasan pos induk } \\
\text { pemadam }\end{array}$ & 8.2 & 7.5 & $7 \cdot 7$ & 8.1 & $7 \cdot 7$ & 7.5 & 46.7 \\
\hline $\begin{array}{l}\text { kebakaran } \quad \text { yg } \\
\text { sudah ada }\end{array}$ & & & & & & & \\
\hline $\begin{array}{l}\text { Pernambahan } \\
\text { jumlah armada }\end{array}$ & 8.5 & $7 \cdot 7$ & $7 \cdot 9$ & 8.5 & $7 \cdot 9$ & $7 \cdot 7$ & 48.3 \\
\hline $\begin{array}{l}\text { Penambahan } \\
\text { jumlah } \\
\text { infrastruktur } \\
\text { pemadam } \\
\text { kebakaran }\end{array}$ & 8.9 & 7.9 & 7.2 & 8.9 & 8.1 & 8.0 & 50.0 \\
\hline $\begin{array}{l}\text { Pemberdayaan } \\
\text { masyarakat } \\
\text { melalui } \\
\text { SATLAKAR }\end{array}$ & 8.7 & 7.6 & $7 \cdot 9$ & 8.7 & $7 \cdot 9$ & 7.7 & 48.6 \\
\hline $\begin{array}{l}\text { Keterangan: } \\
\text { A: KeterJangkauan b } \\
\text { B: Kecepatan waktu } \\
\text { C: Kemudahan perla } \\
\text { D: Kemampuan dala } \\
\text { E: Cepat waktu dalar } \\
\text { F: Ketersedian peral }\end{array}$ & $\begin{array}{l}\text { aya pe } \\
\text { ealisas } \\
\text { sanaa } \\
\text { t pem } \\
\text { pema } \\
\text { an \& }\end{array}$ & $\begin{array}{l}\text { gadac } \\
\text { peng } \\
\text { dalan } \\
\text { ama } \\
\text { aman } \\
\text { ateria }\end{array}$ & $\begin{array}{l}\text { laan } \\
\text { pema } \\
\text { kebal } \\
\text { ebak } \\
\text { pend }\end{array}$ & $\begin{array}{l}\text { man } \\
\text { an } \\
\text { ang }\end{array}$ & baka & & \\
\hline
\end{tabular}

Sumber: Data Primer Yang Diolah (2017)

Hasil kajian alternative solusi penanganan bencana kebakaran di Kota Mataram ini memberikan jawaban yang menyatakan bahwa kondisi maupun lokasi Pos Induk Pemadam Kebakaran di Kota Mataram pada saat ini masih layak/mampu melayani/menjangkau seluruh wilayah Kota Mataram. Maka untuk memberikan solusi terbaik bagi penanganan bencana kebakaran di Kota Mataram ke depan adalah dengan penambahan jumlah infrastruktur pemadam kebakaran, seperti hidran, Alat Pemadam Api Ringan, Smoke Detector, Automatic Reflector dan sebagainya.

\section{SIMPULAN DAN SARAN}

Berdasarkan hasil analisis data dan pembahasan dapat disimpulkan kondisi Pos Induk Pemadam Kebakaran cukup memadai, baik dari aspek kelayakan fisik bangunan maupun kemampuan pelayanan. Frekuensi kejadian kebakaran tahun 2016, rata-rata terjadi 2 kasus setiap bulannya. Daerah rawan kebakaran secara umum didominasi oleh daerah yang memiliki tingkat resiko kebakaran sedang. Alternatif solusi masalah lokasi pos induk pemadam kebakaran yaitu penambahan jumlah infrastruktur pemadam kebakaran, seperti hidran, Alat Pemadam Api Ringan (APAR), Smoke Detector, Automatic Gurgoyle .

Berdasarkan hasil analisis dan pembahasan dan kesimpulan diatas dapat disarankan hal-hal sebagai berikut:

1. Mengingat untuk pembangunan kantor pemadam kebakaran yang baru sesuai dengan hasil analisis yang telah dilakukan yang menunjukan bahwa hal tersebut belum dibutuhkan, maka Pemerintah Kota Mataram untuk menambah pelayanan dan sistim proyeksi kebakaran di Kota Mataram perlu segera menambah jumlah infrastruktur pemadam kebakaran di Kota Mataram, seperti hidran, Alat Pemadam Api Ringan (APAR) Smoke Detector, Automatic Water Reflector, dan sebagainya, menginggat tingkatnya resiko kebakaran, seiring dengan perkembangan aktifitas dan kepadatan Kota Mataram.

2. Penelitian ini masih dapat dikembangkan lagi dengan mengambil lokasi penelitian di tempat lain atau lebih diperdalam lagi dengan menggunakan metode lain dalam pengambilan keputusan pemecahan masalahnya, seperti Analisis SWOT dengan pemutahiran strategi prioritas menggunakan pendekatan AHP.

\section{UCAPAN TERIMA KASIH}

Tim penulis mengucapkan terima kasih kepada LPPM UM Mataram yang telah mendanai penelitian ini.

\section{DAFTAR RUJUKAN}

[1] Walpole, Ronald E., dan Raymond H. Myers, 1986, Ilmu Peluang Dan Statistika untuk Insinyur dan Ilmuwan, Penerbit ITB, Bandung

[2] Kantor Pemadam Kebakaran Kota Mataram, 2016, Dokumen Laporan Kantor Pemadaman Kebakaran Kota Mataram Tahun 2016, Kantor Pemadam Kebakaran Kota Mataram, Mataram

[3] Kantor Pemadam Kebakaran Kota Mataram, 2017, Dokumen Laporan Kantor Pemadaman Kebakaran Kota Mataram Tahun 2017, Kantor Pemadam Kebakaran Kota Mataram, Mataram 